\title{
Trapping of a Borirane Intermediate in the Reductive Coupling of an Arylborane to a Diborene
}

\author{
Alexander Hermann, ${ }^{\dagger}$ Merle Arrowsmith, ${ }^{\dagger}$ Daniel E. Trujillo-Gonzalez, ${ }^{\dagger}$ J. Oscar C. Jiménez- \\ Halla, ${ }^{\ddagger}$ Alfredo Vargas, ${ }^{\S}$ and Holger Braunschweig $*, \dagger$ \\ ${ }^{\dagger}$ Institute for Inorganic Chemistry and Institute for Sustainable Chemistry \& Catalysis with Boron, Julius- \\ Maximilians-Universität Wüzburg, Am Hubland, 97074 Würzburg, Germany \\ ${ }^{\ddagger}$ Departamento de Química, División de Ciencias Naturales y Exactas, Universidad de Guanajuato, Noria Alta S/N, \\ Col. Noria Alta, 36050 Guanajuato, GTO, Mexico \\ $\S$ Department of Chemistry, School of Life Sciences, University of Sussex, Brighton BN1 9QJ, Sussex, United \\ Kingdom
}

\section{Supporting Information Placeholder}

\begin{abstract}
The reductive coupling of an NHC-stabilized aryldibromoborane yields a mixture of trans- and cis-diborenes in which the aryl groups are coplanar with the diborene core. Under dilute reduction conditions two diastereomers of a borirane-borane intermediate are isolated, which upon further reduction give rise to the aforementioned diborene mixture. DFT calculations suggest a mechanism proceeding via nucleophilic attack of a dicoordinate borylene intermediate on the aryl ring and subsequent intramolecular B-B bond formation.
\end{abstract}

Since the 2007 isolation of the first diborene, (IDip) ${ }_{2} \mathrm{~B}_{2} \mathrm{H}_{2}$ (IDip = 1,3-bis(diisopropylphenl)imidazol-2-ylidene), from the reduction of (IDip)BBr ${ }_{3}$ coupled with radical hydrogen abstraction, ${ }^{1}$ much progress has been made in the synthesis of doubly base-stabilized diborenes. $^{2}$ Whereas N-heterocyclic carbene (NHC)-stabilized diborenes, $(\mathrm{NHC})_{2} \mathrm{~B}_{2} \mathrm{R}_{2}$ ( $\mathrm{R}=$ alkyl, (hetero)aryl), are generally obtained from the reductive coupling of $(\mathrm{NHC}) \mathrm{BRX}_{2}(\mathrm{X}=$ halogen $),{ }^{3-6}$ the synthesis of phosphine-stabilized ${ }^{7-10}$ and unsymmetrical diborenes ${ }^{11-13}$ relies on the reduction of dihalodiborane precursors containing a preexisting B-B single bond. While these latter reductions proceed via a relatively straightforward (consecutive or concerted) halogen abstraction process, the reductive coupling of $(\mathrm{NHC}) \mathrm{BRX}_{2}$ to diborenes presents far more complex mechanistic possibilities. In a first step, a one-electron reduction would generate a boryl radical (A), ${ }^{14}$ which could undergo either homocoupling to the diborane (B), the two-electron reduction of which yields the diborene (Scheme 1a, path 1), or a second one-electron reduction to generate a transient dicoordinate borylene (C), ${ }^{15}$ the dimerization of which leads to the diborene (Scheme 1a, path 2), or a complex combination of both pathways.

In 2011 we reported evidence for a borylene-based mechanism: upon reducing $(\mathrm{IMe}) \mathrm{BHCl}_{2}$ (IMe $=1,3$-dimethylimidazol-2ylidene) with sodium naphthalenide (NaNaph), borirane I was isolated (Scheme 1b), which may be viewed as the trapping product of borylene (C) with naphthalene. ${ }^{16}$ Curran and Lacôte, who were the first to report transient NHC-stabilized boryl radicals, ${ }^{17,18}$ questioned this hypothesis, stating that I could equally result from

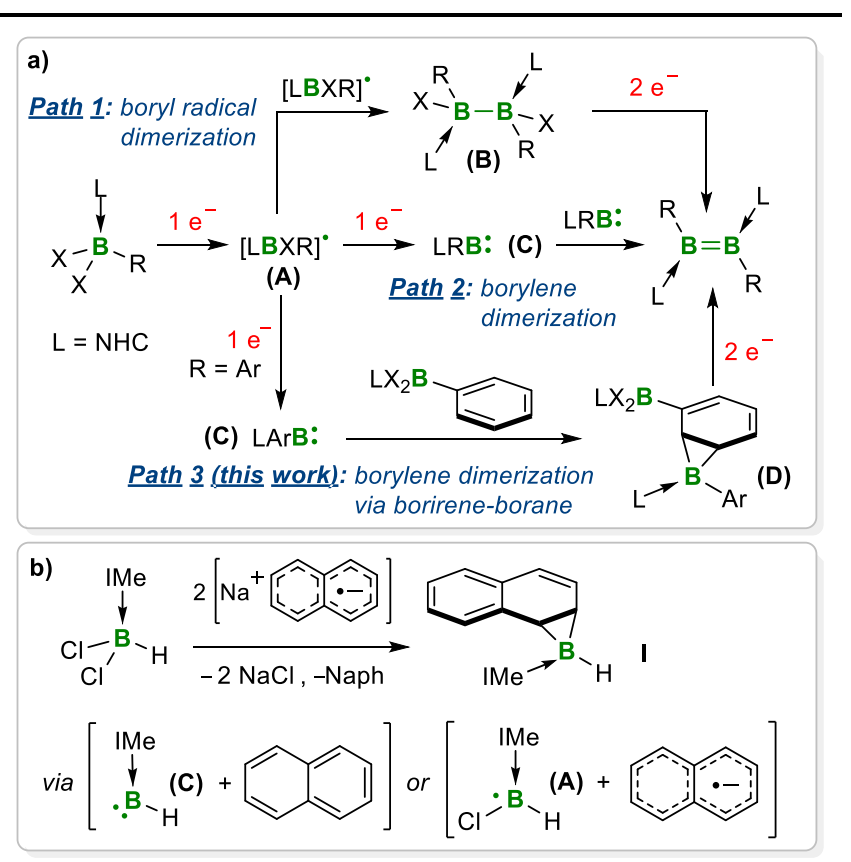

Scheme 1. a) Possible pathways in the reductive coupling of (NHC)BRX $\mathrm{N}_{2}$ to diborenes. b) Reduction of (IMe) $\mathrm{BHCl}_{2}$ to borirane I with sodium naphthalenide. IMe $=1,3$-dimethylimidazol-2ylidene; Naph = naphthalene.

the coupling of boryl radical (A) with $[\mathrm{Naph}]^{--}$(Scheme 1b), followed by one-electron reduction. ${ }^{19}$ The authors based their mechanism on the reduction of $(\mathrm{IMe}) \mathrm{BH}_{2} \mathrm{Cl}$ with $\mathrm{NaNaph}$, which yielded the diborane (IMe) ${ }_{2} \mathrm{~B}_{2} \mathrm{H}_{4}$ through radical homocoupling of $\left[(\mathrm{IMe}) \mathrm{BH}_{2}\right]^{\circ}$, as well as a product of heteroradical coupling between [(IMe)BH$\left.]_{2}\right]^{\circ}$ and $[\mathrm{Naph}]^{\circ}$. While their study did not refute the possibility of a borylene-based reaction directly, other studies have shown that transient dicoordinate borylenes (C) tend to undergo intramolecular ligand $\mathrm{C}-\mathrm{H}$ or $\mathrm{C}-\mathrm{C}$ bond activations rather than borylene dimerization. ${ }^{20-24}$ However, (C) may be trapped and 


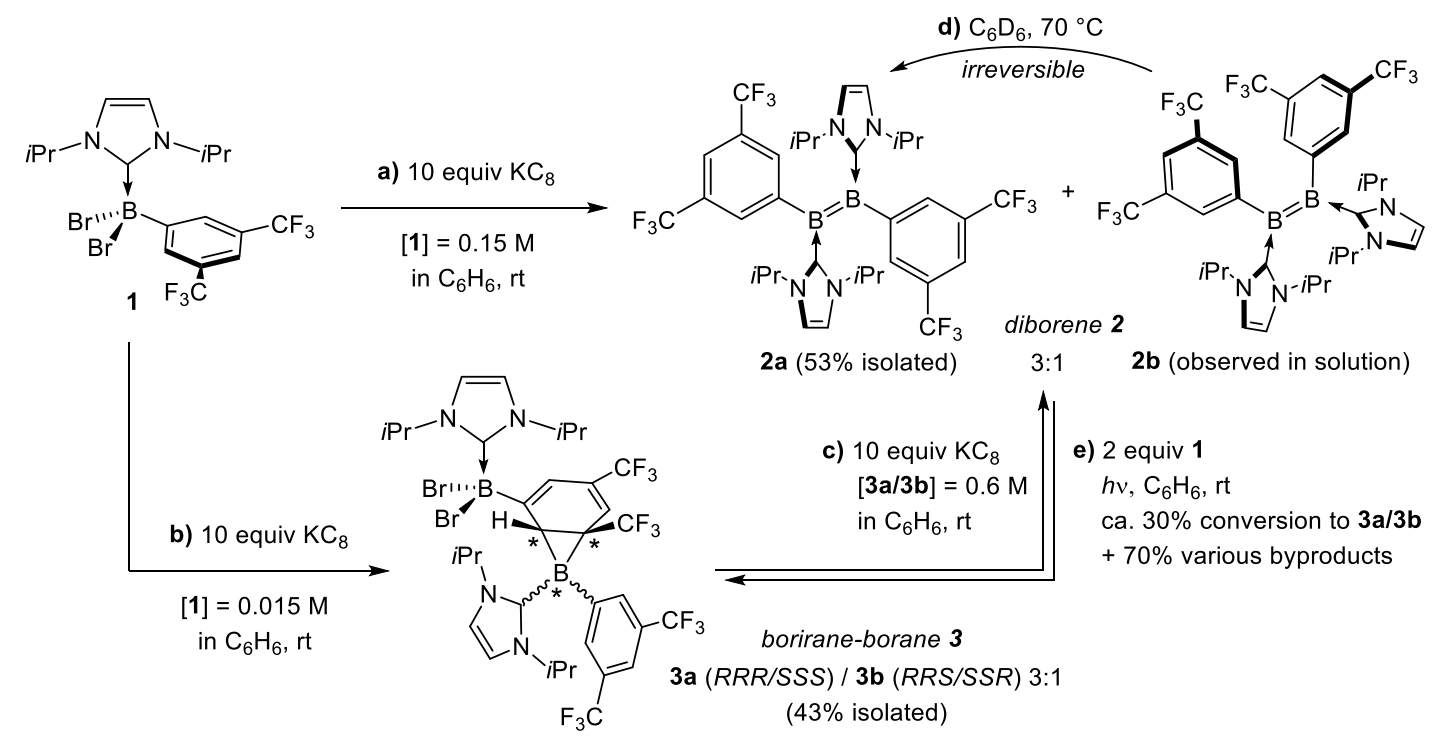

Scheme 2. Direct and stepwise reduction of $\mathbf{1}$ to diborene $\mathbf{2 a} / \mathbf{2 b}$ via borirane-borane intermediate $\mathbf{3 a} / \mathbf{3 b}$.

isolated with an additional small donor ligand $\left(\mathrm{NHC}, \mathrm{PR}_{3}, \mathrm{CO}\right.$, $\left.\mathrm{CNR}, \mathrm{N}_{2}\right) \cdot{ }^{24-28}$ In this work we show an alternative pathway in the reductive coupling of a NHC-stabilized aryldihaloborane to a diborene via an intermediate borirane-borane species (Scheme 1a, path 3), the configuration of which determines whether the transor the cis-diborene is obtained, and probe the reduction mechanism via DFT calculations

The reduction of a $0.15 \mathrm{M}$ solution of $(\mathrm{I} i \mathrm{Pr}) \mathrm{BAr}^{\mathrm{F}} \mathrm{Br}_{2}(\mathbf{1}, \mathrm{I} i \mathrm{Pr}=$ 1,3-diisopropylimidazol-2-ylidene; $\mathrm{Ar}^{\mathrm{F}}=3,5$-bis(trifluoromethyl)phenyl) ${ }^{29}$ in $\mathrm{C}_{6} \mathrm{H}_{6}$ with 10 equiv. $\mathrm{KC}_{8}$ resulted in a deep purple suspension. Recrystallization from benzene afforded purple crystals of diborene $2\left(\delta_{11 \mathrm{~B}}=26 \mathrm{ppm}\right)$ in $53 \%$ isolated yield (Scheme 2a). X-ray crystallographic analysis of 2 revealed a diborene in which the $\mathrm{Ar}^{\mathrm{F}}$ rings are trans to each other and coplanar with the $>\mathrm{B}=\mathrm{B}<$ core (Fig. 1b).$^{30}$ This coplanar arrangement is also found in NHC-stabilized diborenes with unsubstituted or metasubstituted heteroaromatic substituents, ${ }^{3,6}$ while diborenes with ortho-substituted (hetero)aromatic substituents tend towards a perpendicular arrangement. ${ }^{4,6}$ Consequently, the coplanarity of the diborene unit and the (hetero)aromatic substituents in the solid state is governed by steric rather than electronic factors. However, since 2 displays only a single ${ }^{19} \mathrm{~F}$ NMR resonance at $-62.9 \mathrm{ppm}$ the aryl substituents are likely freely rotating in solution.

DFT calculations in the gas phase at the OLYP/TZ2P level of theory surprisingly provided an optimized structure in which the aryl rings are not coplanar with the $>\mathrm{B}=\mathrm{B}<$ core (see Supporting Information for further details). Taking into account short-range dispersion forces, calculations at the $\omega-\mathrm{B} 97 \mathrm{XD} / 6-31 \mathrm{G}(\mathrm{d})$ level of theory provided a planar structure in agreement with the X-ray crystallographic data, showing once more the importance of dispersion forces in enforcing the solid-state geometry of lowvalent compounds. ${ }^{31}$ Independent of the level of calculation chosen, the HOMO of $\mathbf{2 a}$ is mainly located at the $\mathrm{B}=\mathrm{B}$ double bond whereas the LUMO is delocalized over the $\pi^{*}$ system of both $\operatorname{Ar}^{\mathrm{F}}$ rings with a strong $\mathrm{B}-\mathrm{C}_{\text {aryl }} \pi$-bonding component (Fig. 2, compare Fig. S55 in the SI). In accordance with its intense purple color, 2 a shows a strong absorption maximum at $\lambda_{\max }=576 \mathrm{~nm}$, in the same region as other NHC-stabilized diborenes, ${ }^{6}$ with a shoulder at $\lambda_{2}=$ $480 \mathrm{~nm}$. The calculated spectrum of $\mathbf{2 a}$ reproduces the experimental absorption quite well $\left(\lambda_{\max }=600 \mathrm{~nm}\right)$, albeit with redshifted features, a common result of qualitative TDDFT. The main absorption corresponds mainly to the HOMO $\rightarrow$ LUMO transition a)

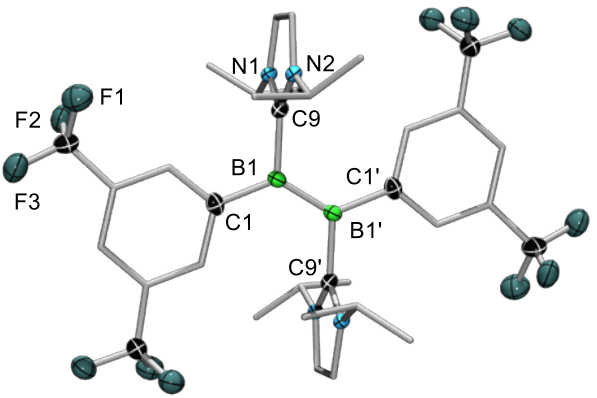

b)

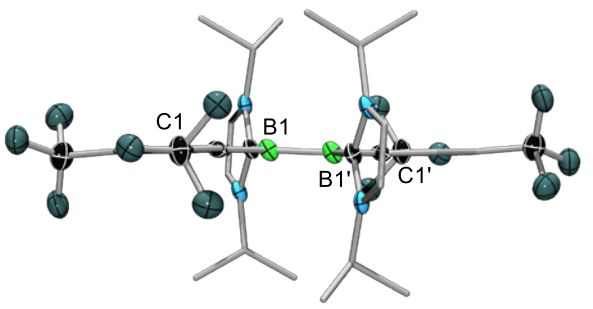

Figure 1. a) Crystallographically-derived molecular structure of 2a. b) View showing the coplanarity of the diborene and aryl moieties. Thermal ellipsoids set at $50 \%$ probability. Thermal ellipsoids of ligand periphery and hydrogen atoms omitted for clarity. ${ }^{30}$

$(2.067 \mathrm{eV})$ and the shoulder at lower energy to the $\mathrm{HOMO} \rightarrow \mathrm{LUMO}+3$ transition (Fig. 2).

Fractional crystallization of the filtrate from the isolation of 2 (Scheme 2a) also yielded a small crop of colorless crystals $(7 \%)$, the NMR spectrum of which revealed the presence of two diastereomers, 3a $\left(75 \%, \delta_{11 \mathrm{~B}}=-3.1,-27.8 \mathrm{ppm}\right)$ and $\mathbf{3 b}\left(25 \%, \delta_{11 \mathrm{~B}}\right.$ $=-3.1,-26.4 \mathrm{ppm})$. The solid-state structure of the major isomer, 3a (Fig. 3), shows the trapping of a formal ( $\mathrm{I} i \operatorname{Pr}) \mathrm{Ar}^{\mathrm{F}} \mathrm{B}$ : borylene moiety by the aryl ring of $\mathbf{1}$, akin to that shown in Scheme $1 \mathrm{~b} .{ }^{16}$ While 3 presents three stereogenic centers in C18, C23 and B1, the syn-selectivity of the trapping reaction leads to only two possible diastereomers: 3a $(R R R / S S S)$, depicted in Fig. 3 and $\mathbf{3 b}(R R S / S S R)$. 


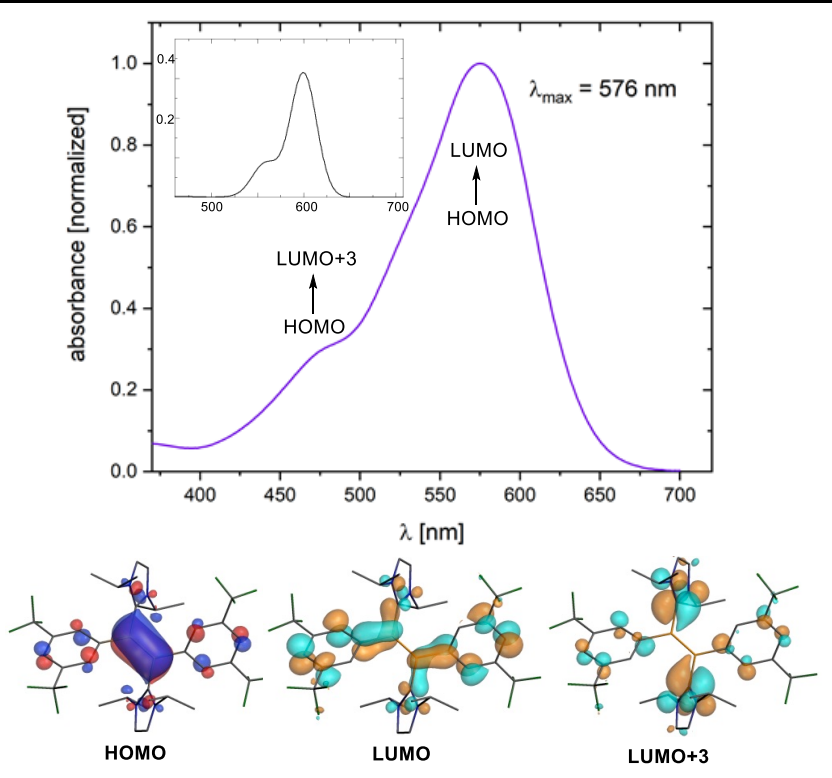

Figure 2. Experimental absorption spectrum of 2a with calculated spectrum at the OLYP/TZ2P level of theory in inset, and plots of the frontier MOs corresponding to the main transitions.

The identity of each diastereomeric pair was ascertained by a ROESY experiment (see Fig. S21 in the SI). For 3a, the proton at $\mathrm{C} 23\left(\delta_{1 \mathrm{H}}=2.99 \mathrm{ppm}\right)$ shows a cross-peak to the ortho-protons of the $\operatorname{Ar}^{\mathrm{F}}$ group bound to $\mathrm{B} 1\left(\delta_{1 \mathrm{H}}=8.90 \mathrm{ppm}\right)$, suggesting their spatial proximity, as would only occur in the $(R R R / S S S)$

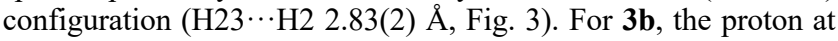
$\mathrm{C} 23\left(\delta_{1 \mathrm{H}}=3.26 \mathrm{ppm}\right)$ displays no such correlation, and therefore likely belongs to the $(R R S / S S R)$ diastereomeric pair.

Compound 3 was isolated in higher yield (43\%) by carrying out the reduction of 1 with $\mathrm{KC}_{8}$ under dilute conditions $(0.015 \mathrm{M}$, Scheme $2 b)$. This observation led us to postulate that $\mathbf{3}$ may be an intermediate in the formation of diborene 2 . Indeed the reduction of isolated $\mathbf{3 a} / \mathbf{3} \mathbf{b}(3: 1)$ with 10 equiv. $\mathrm{KC}_{8}$ under concentrated conditions $\left(0.6 \mathrm{M}\right.$ in $\left.\mathrm{C}_{6} \mathrm{D}_{6}\right)$ resulted in complete conversion to 2 as determined by ${ }^{11} \mathrm{~B}$ NMR spectroscopy (Scheme $2 \mathrm{c}$ ). ${ }^{1} \mathrm{H}$ and ${ }^{19} \mathrm{~F}$ NMR spectra of the filtered reaction mixture, however, evidenced the formation of a second minor species (ca. 25\%) beside the resonances of $2 .{ }^{1} \mathrm{H}$ and ${ }^{19} \mathrm{~F}$ NMR DOSY experiments yielded nearidentical diffusion coefficients for the two species $\left(2: 7.24 \times 10^{-10}\right.$ $\mathrm{m}^{2} \mathrm{~s}^{-1}$; minor product: $6.92 \times 10^{-10} \mathrm{~m}^{2} \mathrm{~s}^{-1}$, see Figs. $\mathrm{S} 33-\mathrm{S} 43$ in the SI), leading us to identify the minor product as the cis isomer of the diborene (Scheme 2). Re-examination of the NMR spectra of the crude reaction mixture from Scheme $2 \mathrm{a}$ also showed the formation of both trans-2 (2a) and cis-2 (2b) in a similar ratio. Above $70{ }^{\circ} \mathrm{C}$ in $\mathrm{C}_{6} \mathrm{D}_{6}, \mathbf{2} \mathbf{b}$, which was calculated to be $2.3 \mathrm{kcal} \mathrm{mol}^{-1}$ higher in energy than $\mathbf{2 a}$, converted irreversibly to $\mathbf{2 a}$ (Scheme 2d, see Fig. $\mathrm{S} 44$ in the SI). This also fits with the calculated rotational barrier of $22.3 \mathrm{kcal} \mathrm{mol}^{-1}$ between the two diborene isomers. With $\mathbf{2 a}$ and $\mathbf{2} \mathbf{b}$ being formed in the same ratio as $\mathbf{3} \mathbf{a}$ and $\mathbf{3 b}$, respectively, their formation may be rationalized as resulting from the reduction of one of the two diastereomers, respectively. This hints at an intramolecular reduction process with strong geometric constraints preventing isomerization. It is noteworthy that until now, cisdiborenes were only accessible through the reduction of 1,2dihalodiboranes stabilized by 1,2-bridging ligands, which enforce the cis geometry. 5,9

We carried out DFT calculations aiming to understand both the mechanism of formation of $\mathbf{3}$ and its subsequent conversion to $\mathbf{2}$

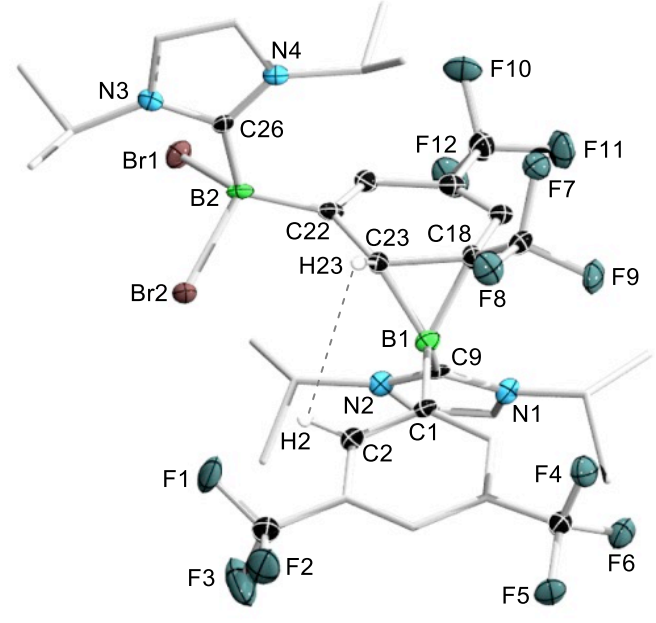

Figure 3. Crystallographically-derived molecular structures of 3a, showing the $\mathrm{H} 23 \cdots \mathrm{H} 2$ spatial interaction with a dotted line. Thermal ellipsoids set at $50 \%$ probability. Thermal ellipsoids of ligand periphery and hydrogen atoms omitted for clarity. Selected bond lengths $(\AA)$ and angles ( $\left.{ }^{\circ}\right)$ : B1-C1 1.598(6), B1-C9 1.597(6), B1-C18 1.637(6), B1-C23 1.610(6), C18-C23 1.581(5), C18-C19 1.454(5), C22-C23 1.488(5), C18-C23-B1 61.6(2), C23-B1-C18 58.2(2), B1-C18-C23 60.2(2).

(see SI Figs. S58-S61 for details). Following the one-electron reduction of 1 to a transient boryl radical, $\mathbf{A}\left(\Delta \mathrm{G}_{\mathrm{R}}=-21.5 \mathrm{kcal} \mathrm{mol}^{-}\right.$ $\left.{ }^{1}\right)$ several pathways were considered. In the first proposal (Scheme $3 \mathrm{a})$, homocoupling of two molecules of $\mathbf{A}$ yields dibromodiborane B $\left(\Delta \mathrm{G}_{\mathrm{R}}=-31.1 \mathrm{kcal} \mathrm{mol}^{-1}\right)$, which undergoes twofold reduction to diborene $2\left(\Delta \mathrm{G}_{\mathrm{R}}=-69.2 \mathrm{kcal} \mathrm{mol}^{-1}\right)$. While thermodynamically viable, this proposal circumvents the isolated intermediate $\mathbf{3}$, which is why two more pathways involving 3 were investigated. The attack of radical $\mathbf{A}$ at the $\mathrm{Ar}^{\mathrm{F}}$ ring of $\mathbf{1}$ to generate the aryl radical C (Scheme 3b), in analogy to the mechanism proposed by Curran and Lacôte for the formation of $\mathbf{I}$ (Scheme 1b), ${ }^{19}$ was rejected as being too endergonic $\left(\Delta \mathrm{G}_{\mathrm{R}}=+21.1 \mathrm{kcal} \mathrm{mol}^{-1}\right)$. In contrast, further reduction of $\mathbf{A}$ yields a transient but energetically accessible borylene $\mathbf{D}\left(\Delta \mathrm{G}_{\mathrm{R}}=+6.8 \mathrm{kcal} \mathrm{mol}^{-1}\right){ }^{32}$ which is stabilized by strong $\pi$ backbonding from the borylene lone pair to the NHC carbene carbon. Such dicoordinate NHC-stabilized singlet borylenes have been studied theoretically by Lu et al, who also found a strong $\pi$

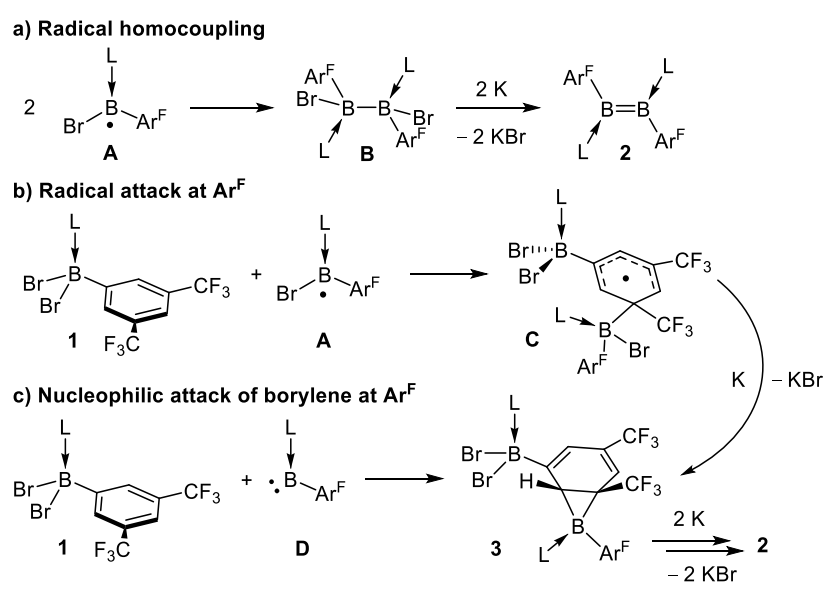

Scheme 3. Mechanisms investigated for the reduction of 1 to 2 . L $=\mathrm{I} i \mathrm{Pr}$. 


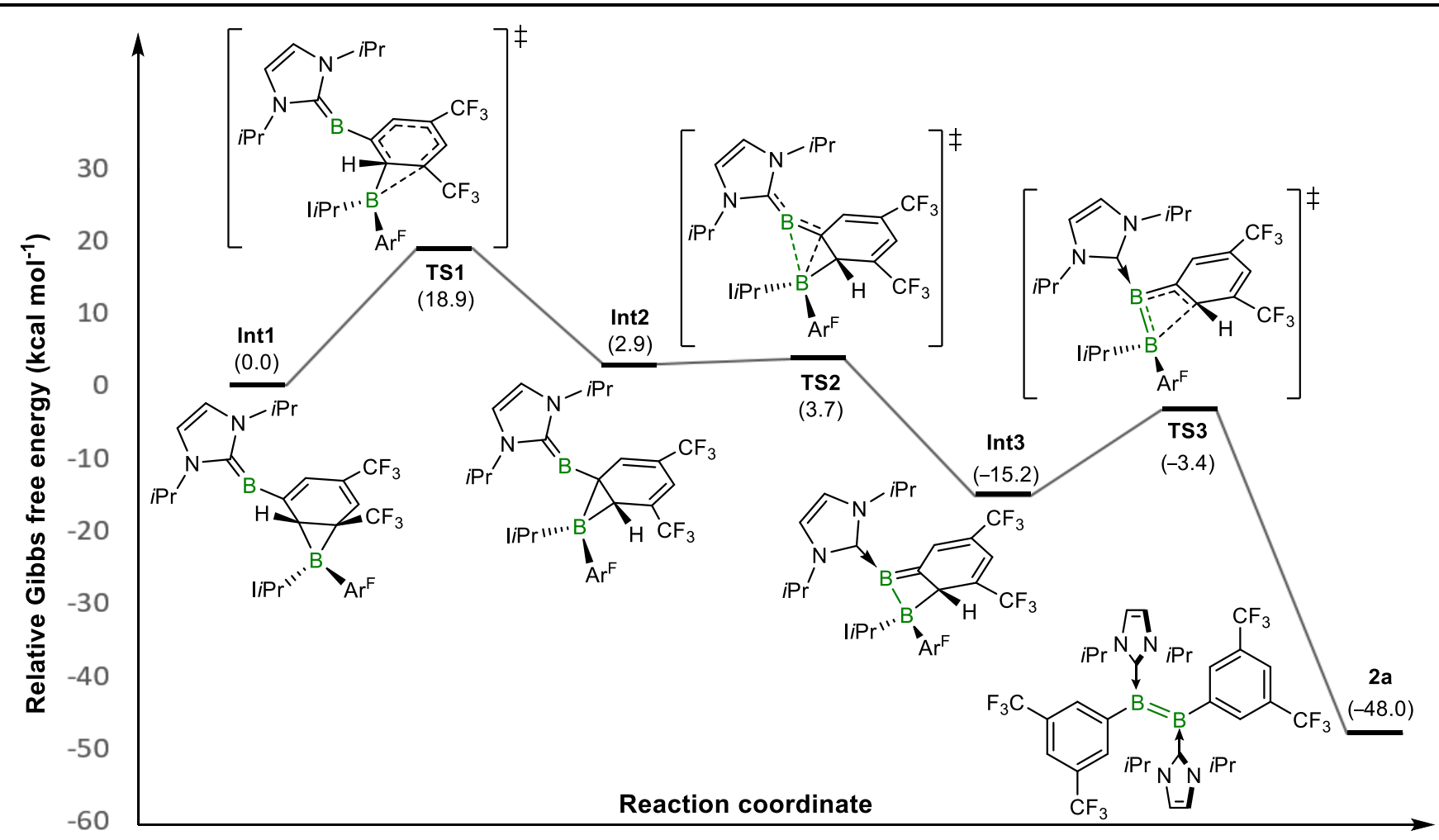

Figure 4. Mechanism of the rearrangement of borirane-borylene intermediate Int1 to diborene 2a calculated at the (PCM:benzene)M06$2 \mathrm{X} / 6-311+\mathrm{G}(2 \mathrm{~d}, \mathrm{p}) / / \mathrm{M} 06-2 \mathrm{X} / 6-31+\mathrm{G}(\mathrm{d})$ level of theory. Relative Gibbs free energies in parentheses $\left(\mathrm{kcal} \mathrm{mol}^{-1}\right)$.

backbonding component. ${ }^{33}$ The nucleophilic attack of $\mathbf{D}$ at the $\mathrm{Ar}^{\mathrm{F}}$ ring of 1 generates 3 (Scheme 3c) in an overall highly exothermic

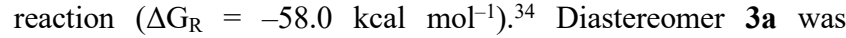
calculated to be $1.7 \mathrm{kcal} \mathrm{mol}^{-1}$ more stable than $\mathbf{3 b}$, thereby accounting for the 3:1 diastereomeric ratio of $\mathbf{3 a}$ and $\mathbf{3 b}$ observed experimentally. The twofold reduction of $\mathbf{3 a}$ results in the boriraneborylene Int1 $\left(\Delta \mathrm{G}_{\mathrm{R}}=-25.6 \mathrm{kcal} \mathrm{mol}^{-1}\right)$. From Int1 the stepwise haptotropic migration of the B2 fragment, which eventually yields diborene 2 , is highly exergonic $\left(\Delta \mathrm{G}_{\mathrm{R}}=-48.0 \mathrm{kcal} \mathrm{mol}^{-1}\right.$, Fig. 4$)$. In the first rate-limiting step $\left(\Delta \mathrm{G}^{\neq}=18.9 \mathrm{kcal} \mathrm{mol}^{-1}\right)$, the borirane ring migrates from the 2,3-position of the dearomatized $\mathrm{Ar}^{\mathrm{F}}$ ring to the thermodynamically slightly less favored 1,2-position (Int2, $\Delta \mathrm{G}_{1}=$ $\left.+2.9 \mathrm{kcal} \mathrm{mol}^{-1}\right)$. This is followed by a quasi barrierless $\left(\Delta \mathrm{G}^{\neq}=0.8\right.$ $\mathrm{kcal} \mathrm{mol}^{-1}$ ) migration of $\mathrm{B} 2$ from the ipso- $\mathrm{Ar}^{\mathrm{F}}$ carbon to $\mathrm{B} 1$ to form a 1,2-diborete ring fused with $\operatorname{Ar}^{\mathrm{F}}$ (Int2, $\Delta \mathrm{G}_{2}=-2.9 \mathrm{kcal} \mathrm{mol}^{-1}$ ). Subsequent breaking of the B2-C23 bond leads to the highly exergonic re-aromatization of the $\mathrm{Ar}^{\mathrm{F}}$ ring and selective formation of $2 \mathbf{a}\left(\Delta \mathrm{G}_{2}=-32.8 \mathrm{kcal} \mathrm{mol}^{-1}\right){ }^{35}$

Cyclic voltammetry of diborene $\mathbf{2 a}$ in THF showed a reversible oxidation wave at $-0.61 \mathrm{~V}$ (vs. the $\mathrm{Fc} / \mathrm{Fc}^{+}$couple), suggesting the possibility of chemical oxidation. We therefore wondered if a comproportionation of diborene $\mathbf{2}$ and borane $\mathbf{1}$ would lead back to borirane-borane 3 . While a mixture of $\mathbf{2}$ and two equivalents of $\mathbf{1}$ in $\mathrm{C}_{6} \mathrm{D}_{6}$ showed no reactivity up to $80^{\circ} \mathrm{C}$, irradiation with UV-light over a period of three days at room temperature resulted in full consumption of $\mathbf{2}$ and one equivalent of $\mathbf{1}$ with formation of ca. $30 \%$ of $\mathbf{3 a} / \mathbf{3 b}$ in a $3: 1$ ratio (Scheme 2e), besides various unidentified products, as determined by ${ }^{1} \mathrm{H}$ NMR spectroscopy. The reduction of $\mathbf{3}$ to $\mathbf{2}$ is thereby at least partially reversible.

To conclude, we have identified a new possible mechanism for the reductive coupling of a $(\mathrm{NHC}) \mathrm{BX}_{2} \mathrm{Ar}$ precursor to the corresponding diborene via a borirane-borane intermediate. DFT calculations show that the latter is likely to result from the formal trapping of a transient dicoordinate borylene, $(\mathrm{NHC})=\mathrm{BAr}$, by the aryl ring of the remaining borane $(\mathrm{NHC}) \mathrm{BX}_{2} \mathrm{Ar}$. The trans- or cisarrangement of the resulting diborene is governed by the stereochemistry of this borirane-borane intermediate. Given that the vast majority of NHC-stabilized diborenes result from the reductive coupling of (hetero)aryldihaloborane precursors, ${ }^{3-6}$ this borirane pathway may well be more broadly relevant, in which case NMR-spectroscopic examination of the crude products of these reductions could reveal the hitherto unknown formation of other cis-diborenes as minor reduction products.

\section{ASSOCIATED CONTENT}

\section{Supporting Information}

The Supporting Information is available free of charge on the ACS Publications website and includes synthetic procedures, NMR spectra of isolated compounds and reaction mixtures, UV-vis spectra, cyclic voltammetry data, crystallographic and computational details (PDF), as well as cif files for all crystallographically characterized compounds.

\section{AUTHOR INFORMATION}

\section{Corresponding Author}

*h.braunschweig@uni-wuerzburg.de

\section{Notes}

The authors declare no competing financial interest.

\section{ACKNOWLEDGMENT}

This project was funded by the European Research Council (ERC) under the European Union Horizon 2020 Research and Innovation Program (grant agreement no. 669054). D.E.T.-J. and J.O.C.J.-H. 
acknowledge 822937 CONACyT fellowship. A.V. acknowledges the University of Sussex for financial support.

\section{REFERENCES}

(1) Wang, Y.; Quillian, B.; Wei, P.; Wannere, C. S.; Xie, Y.; King, R. B.; Schaefer III, H. F.; Schleyer, P. v. R.; Robinson, G. H. A Stable Neutral Diborene Containing a B=B Double Bond. J. Am. Chem. Soc. 2007, 129, 12412-12413.

(2) Arrowsmith, M.; Braunschweig, H.; Stennett, T. E. Formation and Reactivity of Electron-Precise B-B Single and Multiple bonds. Angew. Chem. Int. Ed. 2017, 56, 96-115.

(3) Braunschweig, H.; Dewhurst, R. D.; Hörl, C.; Phukan, A. K.; Pinzner, F.; Ullrich, S. Direct Hydroboration of B=B Bonds: A Mild Strategy for the Proliferation of B-B Bonds. Angew. Chem. Int. Ed. 2014, 53, 3241-3244.

(4) Bissinger, P.; Braunschweig, H.; Damme, A.; Kupfer, T.; Vargas, A. Base-stabilized Diborenes: Selective Generation and $\eta^{2}$ Side-on Coordination to Silver(I). Angew. Chem. Int. Ed. 2012, 51, 9931.

(5) Braunschweig, H.; Krummenacher, I.; Lichtenberg, C.; Mattock, J. D.; Schäfer, M.; Schmidt, U.; Schneider, C.; Steffenhagen, T.; Ullrich, S.; Vargas, A. Dibora[2]ferrocenophane: A CarbeneStabilized Diborene in a Strained cis-Configuration. Angew. Chem. Int. Ed. 2017, 56, 889-892.

(6) Auerhammer, D.; Arrowsmith, M.; Bissinger, P.; Braunschweig, H.; Dellermann, T.; Kupfer, T.; Lenczyk, C.; Roy, D. K.; Schäfer, M.; Schneider, C. Increasing the Reactivity of Diborenes: Derivatization of NHC-Supported Dithienyldiborenes with Electron-Donor Groups. Chem. Eur. J. 2018, 24, 266-273.

(7) Bissinger, P.; Braunschweig, H.; Damme, A.; Hörl, C.; Krummenacher, I.; Kupfer, T. Boron as a Powerful Reductant: Synthesis of a Stable Boron-Centered Radical-Anion Radical-Cation Pair. Angew. Chem. Int. Ed. 2015, 54, 359-362.

(8) Bissinger, P.; Braunschweig, H.; Damme, A.; Kupfer, T.; Krummenacher, I.; Vargas, A. Boron Radical Cations from the Facile Oxidation of Electron-Rich Diborenes. Angew. Chem. Int. Ed. 2014, 53, 5689-5693.

(9) Bissinger, P.; Braunschweig, H.; Celik, M. A.; Claes, C.; Dewhurst, R. D.; Endres, S.; Kelch, H.; Kramer, T.; Krummenacher, I.; Schneider, C. Synthesis of cyclic diborenes with unprecedented cisconfiguration. Chem. Commun. 2015, 51, 15917-15920.

(10) Wang, S. R.; Arrowsmith, M.; Böhnke, J.; Braunschweig, H.; Dellermann, T.; Dewhurst, R. D.; Kelch, H.; Krummenacher, I.; Mattock, J. D.; Müssig, J. H.; Thiess, T.; Vargas, A.; Zhang, J. Engineering a Small HOMO-LUMO Gap and Intramolecular B-B Hydroarylation by Diborene/Anthracene Orbital Intercalation. Angew. Chem. Int. Ed. 2017, 56, 8009-8013.

(11) Lu, W.; Li, Y.; Ganguly, R.; Kinjo, R. Alkene-Carbene Isomerization induced by Borane: Access to an Asymmetrical Diborene. J. Am. Chem. Soc. 2017, 139, 5047-5050.

(12) Lu, W.; Li, Y.; Ganguly, R.; Kinjo, R. Crystalline Neutral Allenic Diborene. Angew. Chem. Int. Ed. 2017, 56, 9829-9832

(13) Stennett, T. E.; Mattock, J. D.; Vollert, I.; Vargas, A.; Braunschweig, H. Unsymmetrical, Cyclic Diborenes and Thermal Rearrangement to a Borylborylene. Angew. Chem. Int. Ed. 2018, 57, 4098-4102.

(14) Su, Y.; Kinjo, R. Boron-containing radical species. Coord. Chem. Rev. 2017, 352, 346-378.

(15) Soleilhavoup, M.; Bertrand, G. Borylenes: An Emerging Class of Compounds. Angew. Chem. Int. Ed. 2017, 56, 10282-10292.

(16) Bissinger, P.; Braunschweig, H.; Kraft, K.; Kupfer, T. Trapping the elusive parent borylene. Angew. Chem. Int. Ed. 2011, 50, 4704-4707.

(17) Walton, J. C.; Makhlouf Brahmi, M.; Fensterbank, L.; Lacôte, E.; Malacria, M.; Chu, Q.; Ueng, S.-H.; Solovyev, A.; Curran, D. P. EPR Studies of the Generation, Structure, and Reactivity of NHeterocyclic Carbene Borane Radicals. J. Am. Chem. Soc. 2010, 132, 2350-2358.

(18) Ueng, S.-H.; Solovyev, A.; Yuan, X.; Geib, S. J.; Fensterbank, L.; Lacôte, E.; Malacria, M.; Newcomb, M.; Walton, J. C.; Curran, D.
P. N-Heterocyclic Carbene Boryl Radicals: A New Class of BoronCentered Radical. J. Am. Chem. Soc. 2009, 131, 11256-11262.

(19) Curran, D. P.; Boussonnière, A.; Geib, S. J.; Lacôte, E. The Parent Borylene: Betwixt and Between. Angew. Chem. Int. Ed. 2012, 51, 1602-1605.

(20) Grigsby, W. J.; Power, P. P. Isolation and Reduction of Sterically Encumbered Arylboron Dihalides: Novel Boranediyl Insertion into C-C o-Bonds. J. Am. Chem. Soc. 1996, 118, 7981-7988.

(21) Bissinger, P.; Braunschweig, H.; Damme, A.; Dewhurst, R. D. Kupfer, T.; Radacki, K.; Wagner, K. Generation of a CarbeneStabilized Bora-borylene and its Insertion into a $\mathrm{C}-\mathrm{H}$ Bond. J. Am. Chem. Soc. 2011, 133, 19044-19047.

(22) Wang, Y.; Robinson, G. H. N-Heterocyclic Carbene-Main-Group Chemistry: A Rapidly Evolving Field, Inorg. Chem. 2014, 53, 11815.

(23) Arrowsmith, M.; Böhnke, J.; Braunschweig, H.; Gao, H.; Légaré, M.-A.; Paprocki, V.; Seufert, J. Synthesis and Reduction of Sterically Encumbered Mesoionic Carbene-Stabilized Aryldihaloboranes. Chem. Eur. J. 2017, 23, 12210-12217.

(24) Braunschweig, H.; Dewhurst, R. D.; Hupp, F.; Nutz, M.; Radacki, K.; Tate, C. W.; Vargas, A.; Ye, Q. Multiple complexation of CO and related ligands to a main-group element. Nature 2015, 522, 327330.

(25) Braunschweig, H.; Krummenacher, I.; Légaré, M.-A.; Matler, A.; Radacki, K.; Ye, Q. Main-Group Metallomimetics: Transition Metallike Photolytic CO Substitution at Boron.. J. Am. Chem. Soc. 2017, 139, 1802-1805.

(26) Arrowsmith, M.; Auerhammer, D.; Bertermann, R.; Braunschweig, H.; Bringmann, G.; Celik, M. A.; Dewhurst, R. D.; Finze, M.; Grüne, M.; Hailmann, M.; Hertle, T.; Krummenacher, I. Generation of Dicoordinate Boron(I) Units by Fragmentation of a Tetra-Boron(I) Molecular Square. Angew. Chem. Int. Ed. 2016, 55, 14464-14468.

(27) Arrowsmith, M.; Schweizer, J. I.; Heinz, M.; Härterich, M.; Krummenacher, I.; Holthausen, M. C.; Braunschweig, H. Synthesis and Reduction Chemistry of Mixed-Lewis-Base-Stabilized Chloroborylenes. Chem. Sci. 2019, 10, 5095-5103.

(28) Légaré, M.-A.; Bélanger-Chabot, G.; Dewhurst, R. D.; Welz, E.; Krummenacher, I.; Engels, B.; Braunschweig, H. Nitrogen fixation and reduction at boron. Science 2018, 359, 896-900.

(29) Compound $\mathbf{1}$ was synthesized by bromide exchange of the precursor $(\mathrm{I} i \mathrm{Pr}) \mathrm{BAr} \mathrm{F}^{\mathrm{F}} \mathrm{Cat}\left(\mathrm{Cat}=\right.$ catecholato) with $\mathrm{BBr}_{3}$ at $-78{ }^{\circ} \mathrm{C}$ in hexanes See Figs. S48 and S49 in the SI for the crystallographically-derived molecular structures of $(\mathrm{I} i \mathrm{Pr}) \mathrm{BAr}{ }^{\mathrm{F}} \mathrm{Cat}$ and $\mathbf{1}$.

(30) The entire molecule 2a crystallized as twofold disordered in a 89:11 ratio via a mirror plane perpendicular to the ArBBAr plane, traversing the center of the $\mathrm{B}=\mathrm{B}$ bond and including $\mathrm{N} 1$ and $\mathrm{N} 2$. Since 1,2- and 1,3-distance restraints had to be applied throughout, bond lengths and angles of 2a may not be discussed further.

(31) Liptrot, D. J.; Power, P. P. London dispersion forces in sterically crowded inorganic and organometallic molecules. Nature Rev. Chem. 2017, 1, 0004.

(32) The formation of a more stable boryl anion, $\left[(\operatorname{IiPr}) \mathrm{BBrAr}{ }^{\mathrm{F}}\right] \mathrm{K}$, is likely to be more favorable but was not computed here due to uncertainty about the nuclearity of such a species in non-coordinating benzene.

(33) Lu, D.; Hea, Y.; Wu C. Electronic structure of mono(Lewis base)stabilized borylenes. Phys. Chem. Chem. Phys. 2019, 21, 23533-23540

(34) Unfortunately, attempts to trap borylene D by performing the reduction of 1 in the presence of a cyclic (alkyl)(amino)carbene (CAAC) failed, although the corresponding tricoordinate borylene (CAAC)(IiPr)BAr ${ }^{\mathrm{F}}$ (5) could be synthesized from the reduction of (CAAC) $\mathrm{BCl}_{2} \mathrm{Ar}^{\mathrm{F}}$ (4) in the presence of $\mathrm{I} i \mathrm{Pr}$. See Supporting information for synthetic details and Figs. S50-S52 for the crystallographically-derived molecular structures of the (CAAC)BAr ${ }^{\mathrm{F}}$ Cat precursor, and compounds $\mathbf{4}$ and $\mathbf{5}$, respectively.

(35) By a similar mechanism the reduction of $\mathbf{3 b}$ leads selectively to the cis-diborene $\mathbf{2 b}$. 
SYNOPSIS TOC (Word Style "SN_Synopsis_TOC").

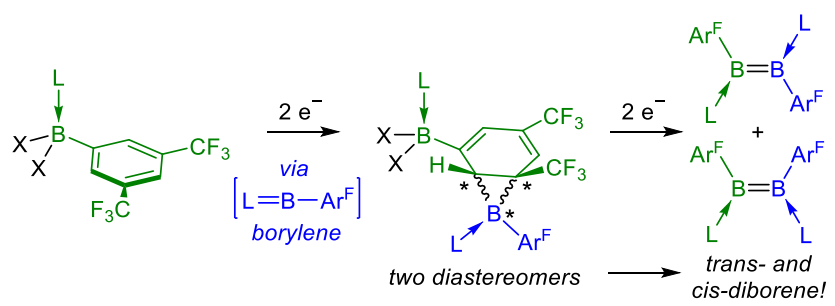

